\title{
Etanol como fonte de energia para veículos elétricos
}

Telmo Ghiorzi*

RESUMO - Há diversos fatores que indicam que a curva de evolução tecnológica e de utilização de veículos elétricos pode ser muito acentuada nos próximos anos. No Brasil, isso provocaria redução na demanda de etanol proporcional à taxa de substituição dos veículos a combustão interna. Este artigo avalia o cenário em que a taxa de substituição dos veículos convencionais no Brasil venha a ser tão alta que, até 2017 , a frota seria composta apenas por veículos elétricos. A partir desta hipótese, é analisada a alternativa de utilizar o etanol para gerar energia elétrica em plantas termoelétricas a ciclo combinado.

Palavras-chave: Etanol. Veículos elétricos. Ciclo combinado. Balanço energético.

\section{PASSADO E PRESENTE DOS VEÍCULOS ELÉTRICOS}

Os primeiros veículos elétricos foram fabricados em 1830, utilizando baterias não-recarregáveis. Tinham melhor desempenho do que seus rivais veículos convencionais (movidos por motores a combustão interna), eram confiáveis, silenciosos e partiam de imediato. Veículos convencionais eram não-confiáveis, exalavam odores desagradáveis, eram ruidosos e precisavam de força humana na manivela para dar partida.

A invenção da partida elétrica, em 1911, e a disponibilidade de gasolina a preços baixos foram fatores importantes na história de predominância dos veículos convencionais sobre os elétricos. Mas o fator determinante foi o peso e volume das baterias. Enquanto um veículo a combustão interna conseguia rodar por $500 \mathrm{~km}$ com 45 litros (cerca de $40 \mathrm{~kg}$ ) de combustível, um veículo elétrico com baterias de chumbo-ácido (tecnologia predominante à época) precisaria de uma bateria com um volume de 1.350 litros (e cerca de $2.700 \mathrm{~kg}$ ) para a mesma autonomia.

Entretanto, há diversos fatores que levam à conclusão de que haverá substituição gradual - e talvez acelerada - dos atuais veículos a combustão interna por veículos elétricos.

A demanda dos usuários, em decorrência da maior atratividade de veículos elétricos com relação à mobilidade individual, aumentará à medida que as seguintes informações forem disseminadas:

a) Veículos elétricos são mais robustos e confiáveis porque seus motores têm, a rigor, apenas uma peça móvel: o rotor que gira dentro do estator. Contra mais de 200

\footnotetext{
* Mestre em engenharia de petróleo pela Unicamp. É aluno especial no Instituto de Eletrotécnica e Energia da Universidade de São Paulo (IEE-USP). Endereço eletrônico: telmo.ghiorzi@uol.com.br.
} 
peças móveis em motor típico de veículos convencionais.

b) Veículos elétricos têm melhor desempenho pois, por característica construtiva, motores elétricos apresentam torque máximo desde rotação zero. Isso faz com que um veículo esportivo de alto desempenho como uma Ferrari F430, mesmo contando com um motor de $490 \mathrm{HP}$, atinja $100 \mathrm{~km} / \mathrm{h}$ em 4,1 s, contra apenas 3,7 s de um Tesla (www.teslamotors.com) cujo motor elétrico gera apenas $285 \mathrm{HP}$ (58\% da F430). Isso se explica pelo fato de que o modelo Tesla entrega um torque constante de $400 \mathrm{Nm}$ entre 0 e $5400 \mathrm{rpm}$. A F430 tem seu torque variando de 0 a $465 \mathrm{Nm}$ entre 0 e $5250 \mathrm{rpm}$.

c) Um motor elétrico com $100 \mathrm{~kW}$ (130 HP) pesa cerca de $20 \mathrm{~kg}$ (LARMINIE, 2003), contra cerca de $200 \mathrm{~kg}$ de um motor de combustão interna com a mesma potência. Esta diferença, em alguns casos, pode compensar o maior peso das baterias e fazer com que o peso total de veículos elétricos seja menor do que o peso dos veículos convencionais.

d) A eficiência de um motor elétrico é da ordem de $90 \%$, contra $20 \%$ de um motor a combustão interna (LARMINIE, 2003). Ou seja, para a mesma quantidade de energia, um veículo elétrico pode rodar uma distância 4 vezes maior do que um veículo convencional, sob as mesmas condições de rodagem. Isto implica menor custo operacional do veículo elétrico.

e) O tempo de carregamento das baterias elétricas é de cerca de 4 a 8 horas. Incomparável com os 5-10 minutos para se reabastecer um tanque de combustível. A substituição do conjunto da bateria, todavia, pode levar menos do que 2 minutos (http://www.betterplace.com/the-solution-switch-stations), e é portanto mais rápida do que reabastecer os tanques de combustível.

Ações de fabricantes também demonstram interesse na substituição da frota. Empresas como Ford, Citroën, VW, Fiat, GM, Nissan, entre outras igualmente grandes, e também montadoras pequenas e independentes (como a própria Tesla Motors), estão aumentando gradativamente a quantidade e a profundidade das informações sobre seus esforços para colocar no mercado veículos elétricos. Esse movimento é um claro indicativo de que há uma competição que vai gerar desenvolvimento tecnológico e consequentemente veículos cada vez melhores e sobretudo mais baratos, à medida que os fatores de escala tiverem lugar. 


\section{IMPACTO DOS VEÍCULOS ELÉTRICOS NA CADEIA DE ETANOL NO BRA-} SIL

A indústria de cana-de-açúcar e produção de açúcar e etanol tiveram início no Brasil em 1530, com as primeiras expedições de Portugal chegando com este propósito ao continente. Mas somente a partir de 1975, com o lançamento do Pro-Álcool, o governo brasileiro deu início a um processo de aumento maciço de produção de etanol a partir da cana. De acordo com o Ministério da Agricultura, Pecuária e Abastecimento (MAPA) há mais de 390 usinas de álcool no país, com produção de 23 bilhões de litros em 2008.

Cerca de 99,6\% da produção de etanol do Brasil serve de combustível para veículos com motores a combustão interna (Balanço Energético Nacional, 2008).

É evidente que, à medida que os veículos elétricos substituírem os veículos a combustão interna, haverá queda proporcional na demanda de etanol.

A redução na demanda de etanol será gradativa e instável, pois ocorrerá na mesma e incerta velocidade de substituição dos veículos a combustão interna. Os preços do etanol sofrerão igual instabilidade. E assim, a atratividade do negócio também ficará instável.

\section{ETANOL COMO FONTE DE ENERGIA PARA VEÍCULOS ELÉTRICOS}

O que se propõe aqui é que à medida que a substituição da frota de veículos a combustão interna provoque redução na demanda de etanol, este etanol excedente seja utilizado para gerar energia elétrica em plantas termoelétricas a ciclo combinado. Seria o que designamos por rota "Etanol-Geração". Observe-se que a produção atual de energia elétrica a partir da queima de bagaço de cana em plantas termoelétricas a ciclo Rankine não seria afetada pela aplicação desta proposta.

O etanol não-consumido em decorrência da redução da frota de veículos movidos a etanol não teria mercado consumidor substituto imediato. Uma possível alternativa seria um processo que produzisse energia elétrica a partir da cana-de-açúcar sem a produção intermediária do etanol. Ter-se-ia neste caso uma planta industrial cujo insumo ou matéria-prima seria a cana-de-açúcar e o produto final seria energia elétrica. Seria a rota "Cana-Geração". O exemplo típico aqui seria a gaseificação da cana (e não gaseificação apenas do bagaço) e uso do gás para gerar energia elétrica em plantas térmicas a ciclo combinado. Esta tecnologia tem se desenvolvido e mostrado viabilidade econômica para o caso em que a matéria-prima é o bagaço (NETO; TOLMASQUIM, 2001).

Entretanto, temos de considerar aqui fatores que não recomendam esta alternativa, em particular aqueles relacionados com o destino - e possível impacto social - do enorme parque 
industrial de produção de etanol (> 350 plantas) e investimento: uma planta de gaseificação (assumindo ser possível gaseificar cana e não apenas bagaço) requer investimentos da ordem de US $\$ 1300 / \mathrm{kW}$, contra US $\$ 750 / \mathrm{kW}$ de uma térmica a ciclo combinado de mesma potência (NETO; TOLMASQUIM, 2001).

Assim, mesmo com maior geração potencial de eletricidade a partir da cana bruta, há fatores tecnológicos, comerciais, ambientais e sociais que recomendam utilizar a alternativa "Etanol-Geração".

\section{BALANÇO ENERGÉTICO}

Não há estudos sobre qual será a velocidade de substituição da frota de veículos convencionais por veículos elétricos. Assume-se então uma taxa cujo resultado seria "toda a frota de veículos leves em 2017 composta de veículos elétricos”. Este seria o cenário mais desfavorável para o setor sucroalcooleiro, pois a demanda de etanol seria reduzida a menos de $1 \%$ das previsões da UNICA (União da Indústria de Cana-de-Açúcar) e do MAPA. Qualquer velocidade intermediária de substituição de frota teria efeitos menos drásticos sobre o segmento.

A energia requerida para alimentar a frota de veículos pode ser calculada tendo por base o tamanho da frota e a distância percorrida por ano. Estes dados estão disponíveis no planejamento energético do Brasil (PDE, 2009). A frota e o consumo de combustível estão abaixo.

TABELA 1 - COMBUSTÍVEIS E FROTA DO BRASIL (PDE, 2009)

\begin{tabular}{l|r|r}
\hline & $\mathbf{2 0 0 8}$ & $\mathbf{2 0 1 7}$ \\
\hline Frota $\left(10^{6}\right.$ carros) & 23,2 & 37,1 \\
Gasolina $\left(10^{9}\right.$ litros) & 18,4 & 14,3 \\
Etanol $\left(10^{9}\right.$ litros) & 23,8 & 54,3 \\
Total de combustível $\left(10^{9}\right.$ litros) & 42,2 & 68,6 \\
Consumo específico $(1 /$ carro/ano) & 1.819 & 1.849 \\
Distância média a $10 \mathrm{~km} / \mathrm{km})$ & $18.190^{*}$ & $\mathrm{NA}$ \\
Distância média $12 \mathrm{~km} / \mathrm{km})$ & $\mathrm{NA}$ & $22.188^{*}$ \\
\hline
\end{tabular}

NOTA: os dados com asterisco ( $($ ) foram calculados, e não obtidos no PDE.

Não há ainda consenso sobre qual valor para consumo específico de veículos elétricos pode ser tomado como realista e representativo. Há valores entre 0,4 MJ/km (EV1 da GM) até 0,72 MJ/km (LARMINIE, 2003). O modelo Tesla apresenta valor de 0,46 MJ $/ \mathrm{km}$. Este valor será utilizado neste artigo por ser representativo de veículo real e disponível para uso comercial.

Pode-se então mostrar qual a energia total que teria sido consumida com a frota de 2008 se ela fosse de veículos elétricos e qual seria o consumo em 2017 se a frota for de veículos elétricos.

196 


$$
\begin{aligned}
& \text { 2008: }(18.190 \mathrm{~km} / \text { carro }) \times\left(23,2 \times 10^{6} \text { carros }\right) \times(0,46 \mathrm{MJ} / \mathrm{km})=194,1 \times 10^{9} \mathrm{MJ} \\
& \text { 2017: }(22.188 \mathrm{~km} / \text { carro }) \times\left(37,1 \times 10^{6} \text { carros }\right) \times(0,46 \mathrm{MJ} / \mathrm{km})=378,7 \times 10^{9} \mathrm{MJ}
\end{aligned}
$$

Note que em ambos os casos, a distância média diária não ultrapassa $60 \mathrm{~km}$. Muito abaixo da autonomia do Tesla e de outros veículos elétricos. Um claro indicativo de que recarregar as baterias durante o período em que os veículos estão parados seria suficiente para o uso típico.

\section{PRODUÇÃO DE ENERGIA}

As hipóteses para se calcular a capacidade de geração estão a seguir:

1) Do total de etanol disponível, apenas a parcela de $90 \%$ produzida pela região centro-sul será considerada;

2) O etanol será utilizado em plantas termoelétricas a ciclo combinado (Brayton + Rankine) de eficiência energética de 58\% (KEHLHOFER, 2009);

3) A energia entregue à rede sofrerá uma perda de 13\% no sistema de transmissão e distribuição, ou seja, eficiência de $87 \%$;

4) A eficiência de carregamento das baterias dos veículos será de $85 \%$, ou seja, $15 \%$ da energia entregue às baterias perde-se no processo de carregamento (LARMINIE, 2003);

5) Densidade do etanol é $0,8 \mathrm{~kg} / \mathrm{l}$;

6) Poder calorífico do etanol é $6.300 \mathrm{kcal} / \mathrm{kg}=26,5 \mathrm{MJ} / \mathrm{kg}$

A energia entregue à rede é então:

Em 2008:

$\left(23,8 \times 10^{9} \mathrm{l}\right) \times(90 \%) \times(0,8 \mathrm{~kg} / \mathrm{l}) \times(26,5 \mathrm{MJ} / \mathrm{kg}) \times(58 \%) \times(87 \%) \times(85 \%)=194,8 \times 10^{9} \mathrm{MJ}$

Em 2017:

$\left(53,2 \times 10^{9} \mathrm{l}\right) \times(90 \%) \times(0,8 \mathrm{~kg} / \mathrm{l}) \times(26,5 \mathrm{MJ} / \mathrm{kg}) \times(50 \%) \times(87 \%) \times(85 \%)=435,3 \times 10^{9} \mathrm{MJ}$ 
Assim, em 2008, se a frota fosse de veículos elétricos, o etanol sozinho poderia alimentá-la. Em 2017, sobraria 15\% (453/378 = 1,15), ou seja, cerca de 8 bilhões de litros de etanol. A conclusão é que a produção de etanol do Brasil pode mover toda a sua frota de veículos leves ainda antes de 2017. Portanto a substituição gradual da frota e consequente redução da demanda de etanol não afetariam este segmento industrial se o etanol fosse direcionado para produzir energia elétrica.

\section{CONCLUSÃO}

Veículos elétricos estão já disponíveis e rodando em diversas partes do mundo. Sua curva de aprendizado e utilização pode sofrer crescimento intenso nos próximos anos. Os principais fatores para este eventual crescimento intenso estão relacionados à demanda potencialmente maior dos condutores por este tipo de veículo (mais rápido, mais robusto e de menor custo operacional), direcionamento dos fabricantes de veículos para esta tecnologia, e políticas públicas que favorecem a preservação do ambiente e dos recursos energéticos.

A produção de etanol, hoje 99,6\% direcionada para veículos a combustão interna, poderia ver sua demanda reduzida na mesma proporção em que ocorreria a substituição da frota por veículos elétricos.

Assumindo que toda a frota seria substituída por veículos elétricos até 2017, e tomando-se as previsões de crescimento de produção de etanol e de crescimento da frota, observa-se que a aplicação do etanol em plantas termoelétricas a ciclo combinado pode gerar toda a energia elétrica para mover a frota brasileira de 2017 em diante. Haveria ainda um excedente de 8 bilhões de litros de etanol.

É evidente que esta mudança na cadeia energética para abastecimento de veículos demandaria enormes investimentos em novas plantas termoelétricas, o que implica enormes oportunidades e estímulos para o desenvolvimento tecnológico brasileiro na produção deste tipo de planta.

\section{REFERÊNCIAS}

BALANÇO ENERGÉTICO NACIONAL 2008: ANO BASE 2007. Rio de Janeiro: Empresa de Pesquisa Energética, 2008.

KEHLHOFER, R.; HANNEMANN, F. Combined-cycle gas \& steam turbine power plants. Tulsa, OK (USA): Pennwell Books, 2009.

LARMINIE, J.; LOWRY, J. Electric vehicle technology explained. Chichester, England: John Wiley \& Sons, 2003.

MACEDO, I. As fontes de energia para geração distribuída - Gerando energia elétrica com bio- 
massa da cana: início de um ciclo virtuoso. In: SEMINÁRIO DE GERAÇÃO DISTRIBUÍDA, 2004, Instituto Nacional de Eficiência Energética (INEE), Rio de Janeiro.

NETO, V. C.; TOLMASQUIM, M. T. Avaliação econômica da cogeração em ciclo combinado com gaseificação de biomassa e gás natural no setor sucroalcooleiro. Revista Brasileira de Energia, Rio de Janeiro, v. 8, n. 2, 2001.

PLANO DECENAL DE EXPANSÃO DE ENERGIA (PDE) 2008-2017. Ministério das Minas e Energia. Empresa de Pesquisa Energética (EPE). Rio de Janeiro, 2009.

PLANO NACIONAL DE ENERGIA (PNE) 2030. Ministério das Minas e Energia. Empresa de Pesquisa Energética (EPE). Rio de Janeiro, 2007.

TOLMASQUIM, M. T. Civilização da biomassa - Matriz energética (apresentação em PowerPoint). EPE, Rio de Janeiro, 2007. 
